\title{
The impact of West Nile virus on the abundance of selected North American birds
}

\author{
Ivo M Foppa ${ }^{1 *}$, Raphaelle H Beard ${ }^{1,2}$ and Ian H Mendenhall ${ }^{3,4}$
}

\begin{abstract}
Background: The emergence of West Nile virus (WNV) in North America has been associated with high mortality in the native avifauna and has raised concerns about the long-term impact of WNV on bird populations. Here, we present results from a longitudinal analysis of annual counts of six bird species, using North American Breeding Bird Survey data from ten states (1994 to 2010). We fit overdispersed Poisson models to annual counts. Counts from successive years were linked by an autoregressive process that depended on WNV transmission intensity (annual West Nile neuroinvasive disease reports) and was adjusted by El Niño Southern Oscillation events. These models were fit using a Markov chain Monte Carlo algorithm.

Results: Model fit was mostly excellent, especially for American Crows, for which our models explained between $26 \%$ and $81 \%$ of the observed variance. The impact of WNV on bird populations was quantitatively evaluated by contrasting hypothetical count trajectories (omission of WNV) with observed counts. Populations of American crows were most consistently affected with a substantial cumulative impact in six of ten states. The largest negative impact, almost $60 \%$, was found in Illinois. A regionally substantial decline was also seen for American Robins and House Sparrows, while the other species appeared unaffected.

Conclusions: Our results confirm findings from previous studies that single out American Crows as the species most vulnerable to WNV infection. We discuss strengths and limitations of this and other methods for quantifying the impact of WNV on bird populations.
\end{abstract}

\section{Background}

In 1998, unusual mortality in Domestic Geese (Anser anser) and White Storks (Ciconia ciconia) in Israel was attributed to WNV infection [1,2]. These were the first reports of lethal WNV infection in birds outside the laboratory. The following year, widespread mortality in wild and exotic birds became the key signature of WNV emergence in North America [3]. The WNV variant in North America was closely related to the virus that had been identified in the epizootic in Israel [4]. American Crows (Corvus brachyrhynchos), as well as other members of the crow family (Corvidae), such as Blue Jays, suffered high mortality [5-10]. Crow mortality was proposed as a reliable indicator of WNV activity [11-17]. Like their old-world relatives [18], American Crows invariably succumbed to experimental WNV infection

\footnotetext{
* Correspondence: ivo.foppa@gmail.com

'Department of Epidemiology, Tulane School of Public Health and Tropical Medicine, New Orleans, Louisiana, USA

Full list of author information is available at the end of the article
}

$[19,20]$. Directly monitored populations of these birds suffered catastrophic mortality due to WNV infection $[21,22]$. These observations spawned concerns about the threat WNV might pose to the North American avifauna. While only individual monitoring can offer direct insight into the impact of WNV on bird populations, this approach is impractical for assessing changes on large temporal and geographic scales. Statistical analysis of count data from well-established national or international bird surveillance programs, such as the North American Breeding Bird Survey (BBS), may offer clues on the impact of WNV on seasonal bird populations. Any systematic and substantial demographic impact of WNV on birds should be noticeable in such surveys. Established in 1966 [23], the BBS collects annual abundance data on over 420 bird species along more than 4,100 survey routes, each 24.5 miles long. These routes are primarily surveyed in June [23], coinciding with early seasonal WNV transmission.
C Biomed Central 
Several studies have analyzed the impact of WNV on bird abundance using BBS data. Fujisaki et al. [24], for example, used change point analysis to detect abrupt population changes in bird populations and used the decline of counts of American Crows in Maryland and Virginia in the wake of WNV emergence as a case study. While the resulting change point estimates accurately reflect the time when WNV emerged in these states, the method does not lend itself to impact quantification. Koenig et al. [25] found a significant decline in corvid species between 2004 and 2005, concurrent with widespread transmission in California.

LaDeau et al. [26] used an extrapolation method to estimate the impact of WNV on birds. They fit overdispersed Poisson models to 26 years of BBS count data, adjusting for observer effects and macro-climatological factors. Based on the resulting parameter estimates and covariate profiles after WNV emergence, they constructed hypothetical count trajectories that might have been observed in the absence of WNV and could be contrasted with observed counts. This method found a significant decline in seven species of birds and estimated a regional decline of American Crows by $45 \%$. Wheeler et al. [27] used the same method, in combination with seroprevalence, dead bird surveillance and susceptibility data and found that, besides American Crows, populations of House Finches (Carpodacus mexicanus), Black-crowned Night Herons (Nycticorax nycticorax), Western Scrub Jays (Aphelocoma californica) and Yellow-billed Magpies (Pica nuttalli) were particularly affected by WNV. These studies, however, did not take into account temporal autocorrelation of bird counts that results from the fact that one year's population includes some of previous year's individuals as well as previous year's offspring. An autoregressive model may therefore be more appropriate for the quantification of the impact of WNV than a model that ignores this dependence. The purpose of our study was to quantify the impact of WNV on six North American bird species using an autoregressive approach. First, we fit autoregressive overdispersed Poisson models to annual bird counts that included an indicator of WNV transmission intensity. This type of model is intuitive, as it accounts for the underlying demographic process. Year-to-year changes in bird populations due to WNV are likely mediated by WNV-associated mortality. Using parameter estimates obtained by fitting such models, but omitting terms associated with WNV transmission, we then constructed counterfactual (hypothetical) count trajectories that can be compared to observed counts. The difference between hypothetical and observed counts is interpreted as impact due to WNV. We compare the resulting impact estimates to estimates obtained by two other methods, including one similar to the method used by LaDeau et al [26].

\section{Results and Discussion \\ Model fit and impact estimates}

Counts of all species varied considerably over the 17 year study period. American Crows appeared to decline with the emergence of WNV in Illinois (IL), Louisiana (LA), Maryland (MD) and possibly Florida (FL) (Figure 1). In Massachusetts (MA), both American Robins and House Sparrows appeared to decline once WNV emerged (Figure 1). The count trajectories predicted by the model fit the data overall quite well. Most counts were contained in the $95 \%$ credible interval associated with the corresponding model prediction (Additional File 1, Figures S1-S6). Among the 54 models examined, more than half (29) explained at least $50 \%$ of the total count variance (Table 1). In FL, MA, MD and Minnesota $(\mathrm{MN}), 25 \%$ or more of the variance in American Crow counts was explained by WNV. Similarly high proportions of the variance in the abundance of American Robins was explained by WNV in California (CA), MA, MN and Tennessee (TN). Only in MN, a substantial proportion of the variance in Blue Jay abundancealmost a third-was due to WNV. In IL, WNV accounted for two fifths of the variance in Mourning Doves (Table 1). The impact of WNV on birds varied by species and state. (Figure 2). American Crows suffered a substantial negative impact due to WNV, i.e. 95\% credible intervals did not reach above zero, in six of the ten states (FL, IL, MA, MD, MN and TN). The most deleterious effect was found in IL $(-58 \%$; $95 \%$ CI: $-76 \%,-31 \%)$, where in 2010 less than half of the birds that would have been expected in absence of WNV were counted. In MA (2003: $-41 \%$; $-62 \%,-13 \%)$, MD (2008: $-47 \%$; $-68 \%,-18 \%)$ and $\mathrm{MN}(2010:-50 \%$; $-67 \%$, $-27 \%)$ and TN (2010: $-33 \%$; $-59 \%,-1 \%)$ the largest negative impact was somewhat less dramatic, but still substantial. In most of these cases, with the possible exception of TN, where American Crows appeared to continue their decline in response to $\mathrm{WNV}$, the negative impact of WNV seemed to have stabilized in recent years (not shown). No other species was as consistently affected. American Robins suffered substantially in MA (2010: $-50 \%$; $-70 \%,-23 \%)$, MD (2008: $-23 \%,-41 \%,-2 \%)$ and MN (2007: $-32 \%,-49 \%,-13 \%)$, but in CA their populations thrived after WNV emergence (2010: 51\%; $13 \%, 100 \%)$. House Sparrows were regionally affected, with a more than four fifth decline in MA (2008: -84\%; $-100 \%,-32 \%)$ and reduction by almost two thirds in MN (2010: $-62 \%,-88 \%,-8 \%)$. Like Northern Cardinals and Blue Jays, Mourning Doves appeared mostly unaffected, but in IL their numbers more than doubled (2010: $126 \%$; $34 \%$, 258\%). 


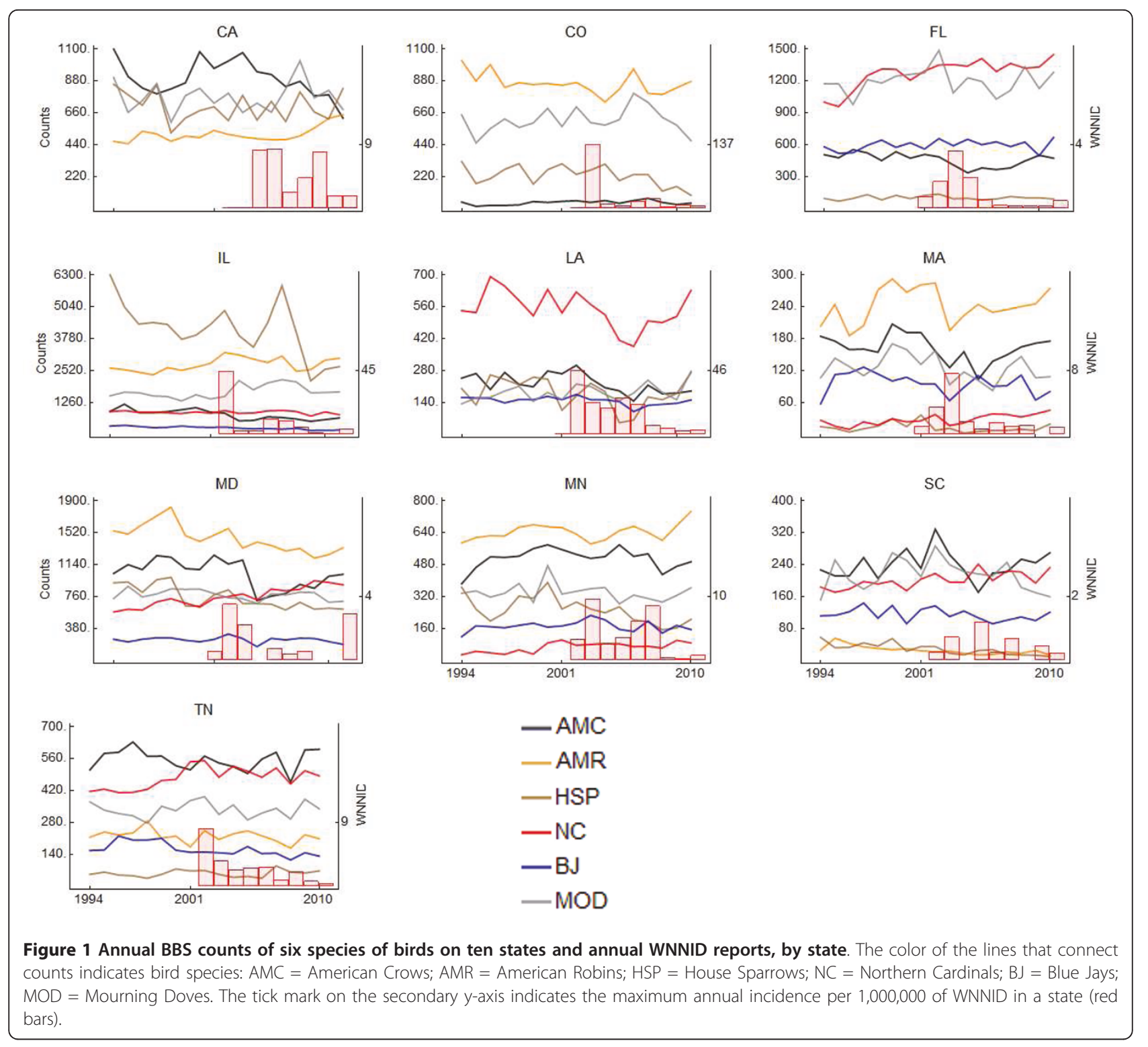

Table 1 Total variance explained (R-squared) by for all state/bird combinations

\begin{tabular}{|c|c|c|c|c|c|c|}
\hline & American Crow & American Robin & House Sparrow & Northern Cardinal & Blue Jay & Mourning Dove \\
\hline CA & $56(4)$ & $77(39)$ & $15(7)$ & $-*$ & - & $19(3)$ \\
\hline $\mathrm{CO}$ & $26(0)$ & $31(0)$ & $46(3)$ & - & - & $19(0)$ \\
\hline $\mathrm{FL}$ & $58(30)$ & - & $49(19)$ & $71(6)$ & $16(6)$ & $36(15)$ \\
\hline IL & $81(13)$ & $61(8)$ & $54(6)$ & $39(16)$ & $90(4)$ & $64(40)$ \\
\hline LA & $60(7)$ & - & $19(13)$ & $31(12)$ & $50(6)$ & $49(22)$ \\
\hline MA & $48(36)$ & $67(52)$ & $51(24)$ & $69(7)$ & $32(12)$ & $48(22)$ \\
\hline MD & $70(31)$ & $76(16)$ & $76(7)$ & $88(0)$ & $19(12)$ & $64(14)$ \\
\hline MN & $69(44)$ & $73(50)$ & $55(12)$ & $75(4)$ & $47(35)$ & $18(10)$ \\
\hline SC & $35(7)$ & $68(0)$ & $69(2)$ & $58(8)$ & $26(6)$ & $45(24)$ \\
\hline TN & $46(23)$ & $57(31)$ & $20(1)$ & $73(3)$ & $58(11)$ & $39(3)$ \\
\hline
\end{tabular}

Total variance in percent explained by the model and variance in percent explained by WNNID (in parentheses).

* Species not analyzed for this state. 


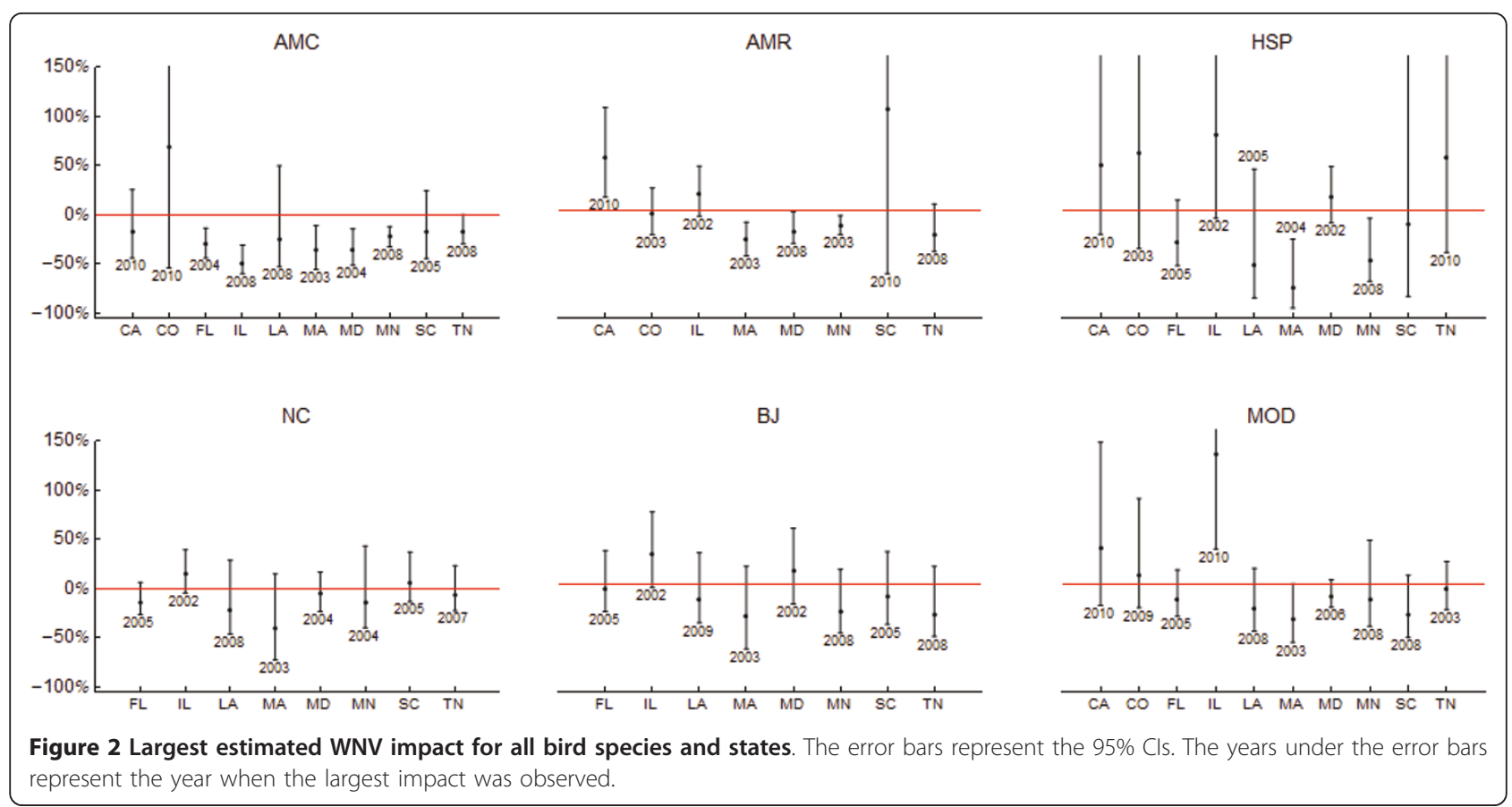

\section{Comparison of three methods}

For American Crows, we compared our method, hence referred to as autoregressive counterfactual, with two methods that are based on extrapolation from pre-WNV emergence data starting with 1982. The extended time period was necessary to ensure that estimation was based on a similar number of data points used with our method (the extrapolation methods do not use data after WNV emergence for estimation). Because of the extended time period, fewer routes with complete data were available and some states needed to be excluded. Thus, only CA, FL, IL, MA, MD, MN and TN could be used for that comparison. Because of the different time periods used for estimation, $r$-squared values cannot directly be compared between the autoregressive counterfactual and the extrapolation methods.

\section{Proportion of the variance explained}

The autoregressive extrapolation method consistently explained a higher proportion of the variance ( $r$ squared) in American Crow counts than the log-linear method. The log-linear and autoregressive extrapolation methods both explained between less than one percent (CA) and almost three fourth or more (MN). The extremely low explanatory power of both extrapolation methods for American Crow counts in CA contrasts with the substantial proportion of the variance explained by the autoregressive counterfactual method. That contrast can be explained by two big count spikes on 1992 and 1994 that are not reflected in the trajectories predicted by both models. Only the second spike was included in the autoregressive counterfactual analysis and was captured quite well by the predicted trajectory. Only in MA (64\% and $67 \%)$ and $\mathrm{MN}(74 \%$ and $80 \%)$ more than half of the variance was explained by the extrapolation models.

\section{Impact estimates}

For the year following highest incidence of WNNID, all methods agreed fairly well with respect to large negative impacts (Figure 3a). In IL, for example, the impact on American Crow counts attributed to WNV was $-49 \%$, $-47 \%$ and $-43 \%$ (autoregressive counterfactual, log-linear extrapolation and autoregressive extrapolation methods) and upper limits of $95 \%$ credible intervals calculated using the different methods were below 0 . Good agreement was also seen, both in posterior means and credible intervals, in the impact estimates for MD and, to a lesser degree for MA. All methods also agreed that no clear impact could be attributed to WNV in CA and $\mathrm{TN}$. For FL and MN, the autoregressive extrapolation estimate was compatible with no impact ( $95 \%$ credible interval including 0 ), while the other estimates suggested a substantial negative impact. It is worth noting that relative to both autoregressive estimates, whose posterior means agreed well, the log-linear extrapolation estimates overestimated the negative impact. For 2010, impact estimates obtained by the three methods agreed considerably less, both in posterior means and credible intervals (Figure $3 \mathrm{~b}$ ). According to the estimates derived by the autoregressive extrapolation method, no relevant impact of WNV on American Crows was detected in any state. For $\mathrm{MN}$, on the other hand, impact estimates derived by the autoregressive counterfactual and the log-linear extrapolation method, respectively, were 
(a)

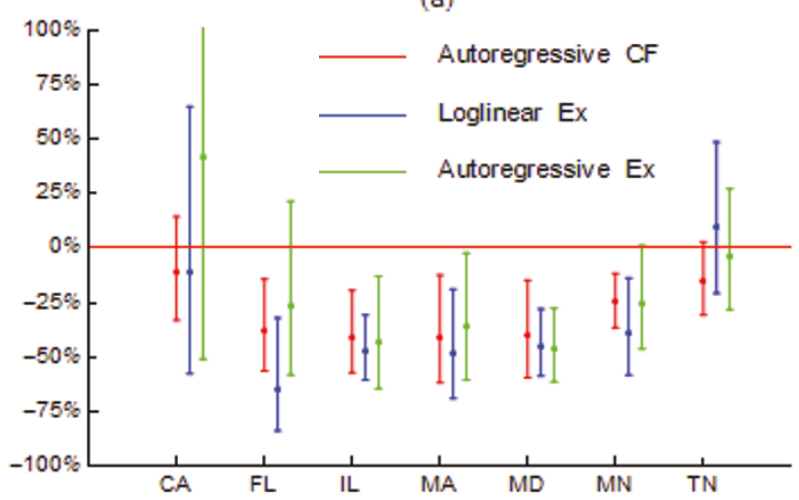

(b)

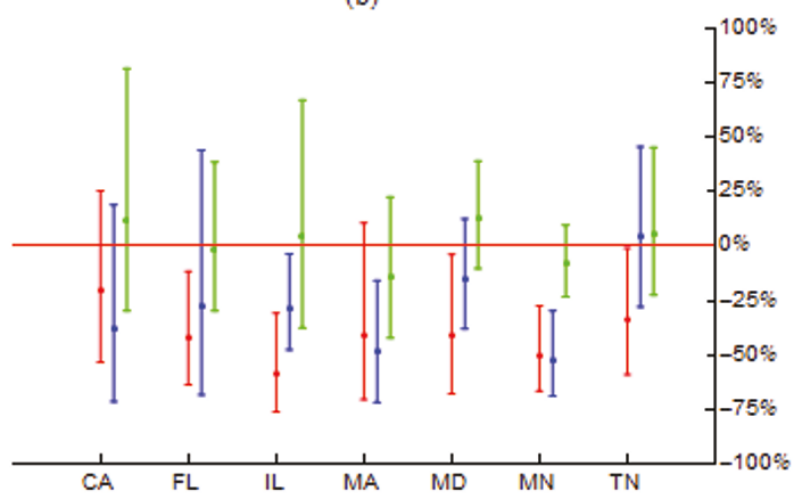

Figure 3 Comparison of unrestricted impact estimates from different models for American Crows, by state. Autoregressive $C F=$ Autoregressive counterfactual method; Loglinear Ex = Loglinear extrapolation method; Autoregressive Ex = Autoregressive extrapolation method. Panel (a) represents the year after the highest WNNID incidence in a state; panel (b) represents 2010.

virtually identical. For most other states, with the exception of TN, the two latter methods agreed on a negative impact of WNV on American Crows, but not size or precision of the respective estimates.

\section{Discussion}

We fit a simple first-order autoregressive Poisson model to BBS count data to construct hypothetical count trajectories ("What would counts have been in the absence of WNV?"). These hypothetical (counterfactual) trajectories served to gauge the impact of WNV on North American bird populations. For most bird-state combinations, our model fit annual counts very well (Additional File 1, Figures S1-S6). Up to $90 \%$ of the total variance in counts was explained by the model (Blue Jays, IL) and up to $50 \%$ of the variance could be attributed to WNV (American Robins, MN). The good fit and the high proportion of variance explained suggests that the model is reasonable.

American Crows appeared to be impacted by WNV particularly severely, which confirms results of previous analyses $[26,27]$ and is consistent with what is known about the sensitivity of that species to WNV $[6,8,11-15,17,19-22]$. We found a regional negative impact of WNV on American Robins, most pronounced in MA, but also in MD and MN. LaDeau et al. [26] also found that these birds suffered from the emergence of WNV. In most states where a substantial impact of WNV on American Crows was observed, that impact seemed to stabilize (Figure 3). This gives rise to hope that the most vulnerable species may not succumb to WNV. The highly abundant House Sparrow, widely considered a nuisance and destructive to the native avifauna, was noted for the first time to suffer substantial losses due to WNV. This species, likely an important reservoir for $\mathrm{WNV}$, is known to suffer mortality from
WNV $[28,29]$. The lack of detected impact on Blue Jays contrasts with their high susceptibility to WNV infection. However, it confirms a similar observation by LaDeau et al. [26]. No obvious biological or ecological mechanism for this observation can be put forward. A modeling artefact also seems unlikely as inspection of the count trajectories does not reveal any systematic declines coinciding with WNV emergence and transmission. Similarly, Northern Cardinals were not obviously impacted by WNV; this species, too, is vulnerable to lethal WNV infection [30]. These observations are somewhat unsettling, as they imply a lack of understanding of some important aspects of the transmission dynamics of this virus. We included Mourning Doves as a species considered not receptive to WNV infection [20] in response to comments by an anonymous reviewer of an earlier version of this manuscript. As expected, no negative impact of WNV on that species was seen. In the contrary, the species surged after WNV emergence in IL. A biological or ecological explanation for the observed positive association between WNV and Mourning Dove abundance may not be obvious. Yet the possibility of an indirect link should not entirely be discarded [31]. For example, a decreasing abundance of American Crows may lead to lower incidence of nestling and egg predation on Mourning Doves and thus to increased abundance.

We compared impact estimates derived with the autoregressive counterfactual method with estimates obtained by two extrapolation methods. For American Crows, the different methods agreed reasonably well on substantial negative impacts. All three methods estimated that between forty and fifty percent of American Crows in IL had vanished by 2003. Clearly, the agreement between the three methods lends credibility to this assessment. Typically, however, impact estimates 
that are based on structurally different statistical models will not quantitatively agree. As all these methods rely on hypothetical population trajectories, that are constructed from observational data, we will never be able to empirically verify which method is the most valid. The method should therefore be chosen a priori, based on previous knowledge. An additional issue pertinent to any attempt to assess the demographic impact of WNV on birds without directly assessing WNV-associated mortality is the possibility of confounding by factors coinciding with WNV transmission. As pointed out by an anonymous reviewer, variations in climate may, for example, directly and simultaneously affect bird communities and WNV transmission intensity. While analyses such as ours enable us to sensitively detect the potential impact of WNV or other agents on birds on a large geographic and temporal scale, in-depth field studies are needed to confirm and identify these biological and ecological mechanisms. But even if impact estimates derived from such methods are confounded in that manner, as long they are based on a valid model, they will likely represent worst case scenarios, i.e. they quantify the impact under the assumption that it is actually due to WNV and not due to the coincident factor.

An assumption of our analysis is that WNV transmission intensity is proportional to an indicator of WNV transmission such as WNNID. That assumption may be problematic for several reasons. First, human infection is epidemiologically insignificant in the sense that it never results in transmission of WNV (people are dead-end hosts of the virus). Yet, human infection with WNV is a reflection of the enzootic process. But how enzootic transmission affects people depends on many factors, including the seasonal dynamics of different vector mosquitoes. In the American Northeast, for example, Culex pipiens mosquitoes, the dominant enzootic and bridge vector there, shift their feeding preference from bird to mammal in late summer [32]. We did not take shifting properties of WNNID as WNV epizootic indicator into account. It is unclear how that phenomenon might be reflected cumulative annual incidence of WNNID. Furthermore, increasing immunity in people could reduce the value of WNNID as indicator for transmission intensity. However, scarce evidence from seroprevalence studies [33,34] indicates that human seroprevalence rarely exceeds $3 \%$, which would likely be insufficient to impact the performance of WNNID as WNV indicator. Second, even though WNV infection, even when not neuroinvasive, is a nationally notifiable disease, reporting may differ by state. As long as the proportion of reported to unreported cases of WNNID does not vary over time, validity of our analysis would not be affected because states are analyzed separately. Third, mosquito-borne transmission is spatially heterogeneous. The extent to which people are affected is also mediated by the proximity of people to transmission foci. A deadly epizootic, leading to massive bird mortality, may not be associated with a spike in WNNID, if it happens away from urban centers with high concentrations of humans and mosquitoes serving as bridge vector. Gingrich et al. [35], for example, documented intense local zoonotic WNV activity in Delaware without a corresponding human epidemic. Even if this is unlikely to happen where Culex pipiens and/or $C x$. quinqufasciatus are the main vector, the spatial scale of our analysis therefore may not adequately reflect the spatial scale of WNV transmission. A local index based on entomological measures (abundance of vector mosquitoes and infection prevalence) would be a much more desirable indicator of transmission intensity. Finally, the demographic impact of WNV on particular avian species may change over time; a detectable prevalence of anti-WNV antibodies in American Crows [36] as well as evidence for an increase of antibody prevalence [37] suggest that possibility. To the extent that this change in susceptibility were substantial, impact estimates might be biased. The good fit of our model with the data, however, supports its validity.

Our methods might be improved by modeling errors that are associated with individual observers. Such errors have the potential to bias population estimates [38] and therefore may be important to include. Other potential model improvements include additional random errors (for example, associated with the change parameter $\kappa$ ) and/or modeling of the probability distribution of the WNV indicator variable.

\section{Conclusions}

Despite potential shortcomings our analytic approach adds to previously used methods. Our impact estimates in some key species were qualitatively similar to estimates reported by other authors. American Crows were most consistently negatively affected by WNV, with an estimated population decline of almost $50 \%$ in IL. Both American Robins and House Sparrows suffered regional losses, while the other species examined were largely unaffected. Future analysis of the impact of WNV on birds should combine an autoregressive model structure with attempts to model known errors associated with the BBS. Large-scale bird count data is a rich source of information on demographic processes that affect bird populations. However, impact estimates, even if derived from structurally valid statistical models, are prone to confounding if accurate and relevant indicators of enzootic WNV transmission are lacking. Ideally, such estimates should be validated with direct field observation. 


\section{Methods \\ Data}

We obtained BBS raw bird count data online from the North American Breeding Bird Survey http://www.pwrc. usgs.gov/bbs/index.html for each of ten states, representing all major regions of the continental United States (in alphabetical order): California (CA), Colorado (CO), Florida (FL), Illinois (IL), Louisiana (LA), Massachusetts (MA), Maryland (MD), Minnesota (MN), South Carolina (SC) and Tennessee (TN). The survey is a collaboration between the U.S. Geological Survey's Patuxent Wildlife Research Center and the Canadian Wildlife Service's National Wildlife Research Centre. Data were obtained on five common North American birds that are known to suffer high mortality from WNV and/or are known to be important amplification hosts of the virus: American Crows (Corvus brachyrhynchos), American Robins (Turdus migratorious), Blue Jays (Cyanocitta cristata), House Sparrows (Passer domesticus) and Northern Cardinals (Cardinalis cardinalis). Mourning Doves (Zenaida macroura) were included as a species that is thought to be unaffected by WNV. Annual counts of American Robins were not analyzed for LA and FL because they were consistently below ten. For both Blue Jays and Northern Cardinals, counts from California and Colorado were not analyzed because they were either consistently below ten or entirely missing. For each species/year combination considered, the sum of all counts from routes with complete data for the years 1994 through 2010 (no missing years) was analyzed. On average, 14 routes were analyzed per state, ranging from five $(\mathrm{CO})$ to 32 (IL), totaling 140 routes.

We used state annual rates of WNV neuroinvasive disease (WNNID) cases as indicators for cumulative transmission intensity of WNV. WNNID reports were obtained from the yearly human case count archives from the CDC WNV Statistics, Surveillance and Control website http://www.cdc.gov/ncidod/dvbid/westnile/ index.htm. The data were obtained from the Encephalitis/Meningitis category in each yearly CDC summary. To obtain rates we divided these numbers by the state mid-year population estimate for that year (U.S. Census Bureau http://www.census.gov/popest/states/NST-annest.html).

El Niño-Southern Oscillation (ENSO) has been found to explain up to $90 \%$ of the annual variation in the productivity of land-breeding birds [39]. We therefore included a dichotomous ENSO variable into our models. The data were obtained from the National Oceanographic and Atmospheric Association (NOAA) and each year in which "abnormal" warming (based on a $+0.5^{\circ} \mathrm{C}$ threshold of the Oceanic Niño Index relative to the 1971-2000 base period [40]) began and continued through the next year was considered an El Niño year http://www.cpc.ncep.noaa.gov/products/analysis_monitoring/ensostuff/ensoyears.shtml.

\section{Data analysis}

The following model was fit to annual counts of the six bird species. Each model was separately fit to time series of counts for all existing bird/state combinations. The annual counts $x_{t}$, for $t \in 2, \ldots, 17$, for each existing bird/ state combination are assumed to be distributed according to Poisson variables whose parameters $\lambda_{t}$ vary around $\mu_{t}$, i.e.

$$
\begin{aligned}
x_{t} & \sim \operatorname{Poisson}\left(\lambda_{t}\right) \\
\log \left(\lambda_{t}\right) & \sim \mathrm{N}\left(\log \left(\mu_{t}\right), \tau\right) .
\end{aligned}
$$

Through the parameters $\mu_{t}$, these counts are modeled as simple first-order autoregressive process [41], i.e.

$$
\mu_{t}=\kappa_{t} \mu_{t-1} .
$$

This type of model will be referred to as an autoregressive counterfactual model. The model is similar to the one proposed by [42] for interspecific demographic interactions. The parameter $\kappa_{t}$, for $t \in 2, \ldots, 16$, represents the annual net change of the population from year $t-1$ to $t$. For each bird/state combination, $\kappa_{t}$ was estimated based on the following model:

$$
\log \left(\kappa_{t}\right)=\beta_{0}+\alpha_{1} y_{t}+\alpha_{2} y_{t-1}+\delta_{1} z_{t}+\delta_{2} z_{t-1},
$$

where $\beta_{0}$ represents the baseline change, $y_{t}$ is the WNNID incidence rate for year $t$ and $z_{t}$ represents the ENSO variable $(1=$ abnormal warming, $0=$ no abnormal warming). Both variables were allowed to have a lagged effect $\left(y_{t-1}\right.$ and $z_{t-1}$, respectively).

Models were fit using a Markov chain Monte Carlo (MCMC) algorithm implemented in WinBUGS (Imperial College and Medical Research Council, UK) [43]. Most parameters were $a$ priori assumed to be distributed according to $\mathrm{N}\left(0,10^{3}\right)$, which corresponds to essentially flat priors over their plausible range (Additional file 2). The empirical posterior distributions of the parameters were obtained from 30,000 MCMC samples, resulting from three chains with 200,000 burn-in iterations and 10,000 samples each (Additional File 2). As determined by visual inspection of chain histories, all models converged. Posterior means and 95\% credible intervals (CIs) were calculated for all parameters of interest.

We estimated the proportion of the total variance explained by final models using a variant of the coefficient of determination or r-squared [44] that was based on the posterior mean of $\mu$, rather than $\lambda$, because overdispersion forces the model to closely reproduce the 
data, giving rise to $\mathrm{r}$-squared values close to one. This calculation was performed for each MCMC iteration. To quantify the proportion of the variance explained by WNNID, we fit also models without WNNID terms. To calculate impact estimates we constructed hypothetical population trajectories $\mu_{t}^{*}$, for $t \in M, \ldots, N$, starting with a state's first year of WNNID reports, $M$. These trajectories are defined by hypothetical expected counts that would be observed in the absence of WNV transmission:

$$
\mu_{t}^{*}=\mu_{M-1} \prod_{t=M}^{N} \kappa_{t}^{*}
$$

and

$$
\kappa_{t}^{*}=\beta_{0}+\delta_{1} z_{t}+\delta_{2} z_{t-1} .
$$

Accordingly, $\kappa^{*}$ is the counterfactual change parameter (no WNNID terms).

These impact estimates will be referred to as autoregressive counterfactual.

We compared the performance of our method with two extrapolation methods. The first of these methods is based on a log-linear model of the counts and is similar to the model used by LaDeau et al. [26]. The log-linear model of the counts has the following form:

$$
\begin{aligned}
x_{t} & \sim \operatorname{Poisson}\left(\lambda_{t}\right) \\
\log \left(\lambda_{t}\right) & =\beta_{0}+\alpha_{1}\left(t-t^{*}\right)+\delta_{1} z_{t}+\delta_{2} z_{t-1}+\varepsilon_{t},
\end{aligned}
$$

where $\alpha_{1}$ is a log-linear trend, centered at $t^{*}$, the midpoint of the data period to which the model was fit and $\varepsilon_{t}$ is a $\mathrm{N}(0, \tau)$ error term. Impact estimates were based on hypothetical count trajectories that were calculated from the linear combinations of covariate values and parameter estimates for the years after WNV emergence. From the resulting hypothetical counts we subtracted the Poisson parameter estimates of the actual counts and divided the result by the hypothetical counts to obtain a proportional impact measure (log-linear extrapolation).

Similarly, autoregressive models ( 2 and 3 , but without WNNID terms) were fit only to pre-emergence counts. Calculation of impact estimates (autoregressive extrapolation) were performed as described for the log-linear model.

The comparison was done using American Crow data. As the extrapolation methods do not use data after WNV emergence for parameter estimation, we included data from 1982 until WNV emergence, resulting in 29 (rather than 17) years of data. As a consequence of using only routes with complete data, fever routes were available for this analysis and three states could not be analyzed. For seven states
(CA, FL, IL, MA, MD, MN and TN) data were available for the comparison of impact estimates. Impact estimates were compared for the year after the highest WNV activity (as measured by WNNID incidence) and for 2010.

\section{Additional material}

Additional file 1: This zipped folder contains the supplemental Figures (Figure 1 suppl.pdf through Figure 6 suppl.pdf) and legends (Supplemental Figure legends 2.pdf).

Additional file 2: This zipped folder contains a sample data file (datamatnew_amclL.dat), WinBUGS code (model 2 a1a2d1d2.txt), R code (calculations AMC IL.txt) and a description of these files (Description of suppl files 2.doc).

\section{Acknowledgements}

This study would not have been possible without the tireless effort of thousands of volunteers who collected BBS data. Comments of several anonymous reviewers of the current and previous versions of the manuscript helped to improve it. The project was supported by a Tulane Research Enhancement Phase II grant.

\section{Author details}

${ }^{1}$ Department of Epidemiology, Tulane School of Public Health and Tropical Medicine, New Orleans, Louisiana, USA. ${ }^{2}$ Dept of Emergency Medicine, Johns Hopkins University School of Medicine, Baltimore, Maryland, USA.

${ }^{3}$ Department of Tropical Medicine, Tulane School of Public Health and Tropical Medicine, New Orleans, Louisiana, USA. ${ }^{4}$ Program in Emerging Infectious Diseases, Duke-NUS Graduate Medical School, Singapore.

\section{Authors' contributions}

IMF designed the study, developed methods, analyzed the data and wrote the manuscript. RHB prepared the data, analyzed the data and contributed to the manuscript. IHM provided ornithological expertise and contributed to the manuscript. All authors read and approved the final manuscript.

Received: 19 January 2011 Accepted: 11 August 2011

Published: 11 August 2011

\section{References}

1. Bin $H$, Grossman $Z$, Pokamunski $S$, Malkinson $M$, Weiss $L$, Duvdevani $P$, Banet C, Weisman Y, Annis E, Gandaku D, Yahalom V, Hindyieh M, Shulman L, Mendelson E: West Nile fever in Israel 1999-2000 - From geese to humans. West Nile Virus: Detection, Surveillance, and Control, Volume 951 of Annals of the New York Academy of Sciences 2001, 127-142.

2. Malkinson M, Banet C, Weisman Y, Pokamonski S, King R, Deubel V: Intercontinental transmission of West Nile virus by migrating white storks. Emerging Infectious Diseases 2001, 7(3):540.

3. ProMED-mail: West Nile-Like Virus - USA (New York City). Promed-mail 1999, 22, 991016212103.

4. Lanciotti RS, Roehrig JT, Deubel V, Smith J, Parker M, Steele K, Crise B, Volpe KE, Crabtree MB, Scherret JH, Hall RA, MacKenzie JS, Cropp CB, Panigrahy B, Ostlund E, Schmitt B, Malkinson M, Banet C, Weissman J, Komar N, Savage HM, Stone W, McNamara T, Gubler DJ: Origin of the West Nile virus responsible for an outbreak of encephalitis in the northeastern United States. Science 1999, 286(5448):2333-2337.

5. CDC: West Nile virus activity-United States, January 1-December 1, 2005. MMWR Morb Mortal Wkly Rep 2005, 54(49):1253-1256.

6. Hochachka WM, Dhondt AA, McGowan KJ, Kramer LD: Impact of West Nile Virus on American Crows in the Northeastern United States, and Its Relevance to Existing Monitoring Programs. EcoHealth 2004, 1:60-68. 7. Komar N: West Nile viral encephalitis. Rev Sci Tech 2000, 19:166-176. 8. Komar O, Robbins MB, Klenk K, Blitvich BJ, Marlenee NL, Burkhalter KL, Gubler DJ, Gonzalvez G, Pena CJ, Peterson AT, Komar N: West Nile virus transmission in resident birds, Dominican Republic. Emerg Infect Dis 2003, 9(10):1299-302. 
9. Ludwig GV, Calle PP, Mangiafico JA, Raphael BL, Danner DK, Hile JA, Clippinger TL, Smith JF, Cook RA, McNamara T: An outbreak of West Nile virus in a New York City captive wildlife population. American Journal of Tropical Medicine and Hygiene 2002, 67:67-75.

10. Reisen W, Lothrop H, Chiles R, Madon M, Cossen C, Woods L, Husted S, Kramer V, Edman J: West Nile virus in California. Emerg Infect Dis 2004 10(8):1369-1378

11. Eidson M, Komar N, Sorhage F, Nelson R, Talbot T, Mostashari F, McLean R: Crow deaths as a sentinel surveillance system for West Nile virus in the Northeastern United States, 1999. Emerging Infectious Diseases 2001, 7(4):615-620.

12. Eidson M, Miller J, Kramer L, Cherry B, Hagiwara Y: Dead crow densities and human cases of West Nile Virus, New York State, 2000. Emerging Infectious Diseases 2001, 7(4):662-664.

13. Eidson M, Schmit K, Hagiwara Y, Anand M, Backenson PB, Gotham I, Kramer L: Dead crow density and West Nile virus monitoring, New York. Emerg Infect Dis 2005, 11(9):1370-5.

14. Johnson GD, Eidson M, Schmit K, Ellis A, Kulldorff M: Geographic prediction of human onset of West Nile virus using dead crow clusters: an evaluation of year 2002 data in New York State. Am J Epidemiol 2006, 163(2):171-80.

15. Julian KG, Eidson M, Kipp AM, Weiss E, Petersen LR, Miller JR, Hinten SR, Marfin AA: Early season crow mortality as a sentinel for West Nile virus disease in humans, northeastern United States. Vector Borne Zoonotic Dis 2002, 2(3):145-55.

16. Roberts RS, Foppa IM: Prediction of equine risk of West Nile virus infection based on dead bird surveillance. Vector Borne Zoonotic Dis 2006, 6:1-6.

17. Watson JT, Jones RC, Gibbs K, Paul W: Dead crow reports and location of human West Nile virus cases, Chicago, 2002. Emerg Infect Dis 2004, 10(5):938-40.

18. Work TH, Hurlbut HS, Taylor RM: Isolation of West Nile virus from hooded crow and rock pigeon in the Nile delta. Proc Soc Exp Biol Med 1953, 84(3):719-22.

19. Brault A, Langevin S, Bowen R, Panella N, Biggerstaff B, Miller B, Komar N: Differential virulence of West Nile strains for American crows. Emerging Infectious Diseases 2004, 10(12):2161-2168.

20. Komar N, Langevin S, Hinten S, Nemeth N, Edwards E, Hettler D, Davis B, Bowen R, Bunning M: Experimental infection of North American birds with the New York 1999 strain of West Nile virus. Emerg Infect Dis 2003, 9(3):311-322.

21. Caffrey C, Smith SCR, Weston TJ: West Nile virus devastates an American crow population. The Condor 2005, 107:128-132.

22. Yaremych SA, Warner RE, Mankin PC, Brawn JD, Raim A, Novak R: West Nile virus and high death rate in American crows. Emerg Infect Dis 2004, 10(4):709-11.

23. Robbins CS, Bystrak D, Geissler PH: The Breeding Bird Survey: Its first fifteen years, 1965-1979. Washington, D.C.: U.S. Dept. of the Interior, Fish and Wildlife Service; 1986.

24. Fujisaki I, Pearlstine EV, Miller M: Detecting population decline of birds using long-term monitoring data. Population Ecology 2008, 50(3):275-284

25. Koenig W, Marcus L, Scott T, Dickinson J: West Nile virus and California breeding bird declines. EcoHealth 2007, 4:18-24.

26. LaDeau SL, Kilpatrick AM, Marra PP: West Nile virus emergence and largescale declines of North American bird populations. Nature 2007, 447(7145):710-3

27. Wheeler S, Barker C, Fang Y, Armijos M, Carroll B, Husted S, Johnson W, Reisen W: Differential impact of West Nile virus on California birds. The Condor 2009, 111:1-20.

28. Eidson M, Kramer L, Stone W, Hagiwara Y, Schmit K, et al: Dead bird surveillance as an early warning system for West Nile virus. Emerging Infectious Diseases 2001, 7(4):631.

29. Langevin SA, Brault AC, Panella NA, Bowen RA, Komar N: Variation in virulence of West Nile virus strains for house sparrows (Passer domesticus). Am J Trop Med Hyg 2005, 72:99-102.

30. Komar N, Panella NA, Langevin SA, Brault AC, Amador M, Edwards E, Owen JC: Avian hosts for West Nile virus in St. Tammany Parish, Louisiana, 2002. Am J Trop Med Hyg 2005, 73(6):1031-7.

31. Ladeau S, Marra P, Kilpatrick A, Calder C: West Nile virus revisited: consequences for North American ecology. BioScience 2008, 58(10):937-946.
32. Kilpatrick AM, Kramer LD, Jones MJ, Marra PP, Daszak P: West Nile virus epidemics in North America are driven by shifts in mosquito feeding behavior. PLOS Biol 2006, 4(4):e82.

33. Mostashari F, Bunning M, Kitsutani P, Singer D, Nash D, Cooper M, Katz N, Liljebjelke K, Biggerstaff B, Fine A, et al: Epidemic West Nile encephalitis, New York, 1999: results of a household-based seroepidemiological survey. The lancet 2001, 358(9278):261-264

34. Loeb M, Elliott S, Gibson B, Fearon M, Nosal R, Drebot M, D'Cuhna C, Harrington D, Smith S, George $P$, et al: Protective behavior and West Nile virus risk. Emerging infectious diseases 2005, 11(9):1433.

35. Gingrich J, O'Connor L, Meredith W, Pesek J, Shriver W: Epidemiology of West Nile Virus: A Silent Epiornitic in Northern Delaware in 2007 without Associated Human Cases. Journal of the American Mosquito Control Association 2010, 26(3):274-286.

36. Wilcox B, Yabsley M, Ellis A, Stallknecht D, Gibbs S: West Nile virus antibody prevalence in American crows (Corvus brachyrhynchos) and fish crows (Corvus ossifragus) in Georgia, USA. Avian diseases 2007, 51:125-128.

37. Reed L, Johansson M, Panella N, McLean R, Creekmore T, Puelle R, Komar N: Declining mortality in American crow (Corvus brachyrhynchos) following natural West Nile virus infection. Avian diseases 2009, 53(3):458-461.

38. Link WA, Sauer JR: A hierarchical analysis of population change with application to Cerulean Warblers. Ecology 2002, 83(10):2832-2840.

39. Nott M, Desante $D$, Siegel R, Pyle P: Influences of the El Niño/Southern Oscillation and the North Atlantic Oscillation on avian productivity in forests of the Pacific Northwest of North America. Global Ecology and Biogeography 2002, 11(4):333-342

40. Xue Y, Smith T, Reynolds R: Interdecadal changes of 30-yr SST normals during 1871-2000. Journal of Climate 2003, 16:1601-1612.

41. Jamieson L, Brooks S: Density dependence in North American ducks. Animal Biodiversity and Conservation 2004, 27:113-128.

42. Freeman S, Newson S: On a log-linear approach to detecting ecological interactions in monitored populations. Ibis 2008, 150(2):250-258.

43. Spiegelhalter D, Thomas A, Best N, Lunn D: WinBUGS User Manual. 2003.

44. Gelman A, Pardoe L: Bayesian measures of explained variance and pooling in multilevel (hierarchical) models. Technometrics 2006, 48(2):241-251.

doi:10.1186/1746-6148-7-43

Cite this article as: Foppa et al:: The impact of West Nile virus on the abundance of selected North American birds. BMC Veterinary Research 2011 7:43.

\section{Submit your next manuscript to BioMed Central and take full advantage of:}

- Convenient online submission

- Thorough peer review

- No space constraints or color figure charges

- Immediate publication on acceptance

- Inclusion in PubMed, CAS, Scopus and Google Scholar

- Research which is freely available for redistribution

Submit your manuscript at www.biomedcentral.com/submit
C Biomed Central 